\title{
The Process of Successful Ageing
}

MARGRET M. BALTES*

and LAURA L. CARSTENSEN†

ABSTRACT

As increasingly more people experience old age as a time of growth and productivity, theoretical attention to successful ageing is needed. In this paper, we overview historical, societal and philosophical evidence for a deep, long-standing ambivalence about human ageing that has influenced even scientific views of old age. In recent years, however, discussion of the psychological and behavioural processes people use to maintain and reach new goals in late life has gained momentum. We contribute to this discussion the metamodel of selective optimisation with compensation, developed by Baltes and Baltes. The model is a metamodel that attempts to represent scientific knowledge about the nature of development and ageing with the focus on successful adaptation. The model takes gains and losses jointly into account, pays attention to the great heterogeneity in ageing and successful ageing, and views successful mastery of goals in the face of losses endemic to advanced age as the result of the interplay of the three processes, selection, compensation, and optimisation. We review evidence from the biological and social science literatures for each component and discuss new research avenues to study the interaction of the three processes.

KEY WORDS - Success, successful ageing, selection, compensation, optimisation.

* Forschungsgruppe Psychologische Gerontologie, Freie Universität Berlin, Ulmenallee 32, $1405^{\circ}$ Berlin, Germany.

$\dagger$ Department of Psychology, Stanford University, Stanford, CA 94305, USA. 


\section{Introduction}

Since its inception, the primary focus of gerontological research has been in decline and loss associated with advanced age (Riley et al. 1994). We neither deny nor minimise the importance of research on age-related decline. The plight of old age is very real, embracing losses in physical, cognitive and social domains. It is not surprising that anticipation of ageing is characterised by anxiety and fear both on the part of the individual (e.g. fear of loss) and on the part of societies (e.g. fears of increased costs and burdens). The plight of ageing, however, is only one side of the coin. The other side involves growth, vitality, striving and contentment.

Discussion of successful ageing inevitably raises concern within and outside the academy. In fact, Cole ( 1983 ) contends that positive portrayals of ageing are potentially as pernicious as negative ones in that they deny the reality of ageing. Cole ( 1983 ) and Rosenmayr (1989), for example, believe that unless this 'enlightened' view of ageing is extended to include the existential challenges of physical and social decline in old age, it may very well have baneful effects. Cole writes: 'The currently fashionable positive mythology of old age shows no more tolerance or respect for the intractable vicissitudes of aging than the old negative mythology ( $1983: 39$ ).

Such concerns are not without merit. However, even though morbidity and mortality rates do increase with age (Brody et al. 1987; Manton and Soldo 1985), we have reached the point in Western societies where the reduction in infant mortality and the compression of morbidity (Fries 1990) allow the majority of people to live out their lives in relatively good physical health (Manton et al. 1993). Recently, several prominent biological researchers and physicians have argued that successful and positive ageing must not be omitted from our conceptions of old age to do justice to its multifaceted nature and vast heterogeneity (Bortz I989; Fries 1990; Rowe and Kahn 1987). In addition, most older people are satisfied with their lives, even more so than their younger counterparts (Herzog and Rodgers $198 \mathrm{I}$ ).

Nevertheless, we agree with critics that the focus on theoretically normative psychological outcomes - rooted primarily in middle-class values and, prototypically, in white, male standards - has seriously limited our understanding of successful ageing. The use of normative outcomes pays only minimal attention to the heterogeneity among and within ageing people (Maddox 1987; Thomae I98I), fails to acknowledge the social construction of old age (Dannefer 1987), and ignores the potential for multiple outcomes (Schaie 1983) and diverse 
standards of success (Boesch r.954). A person living under objectively poor conditions may strive towards self-actualisation, another living in an objectively good situation may experience ageing as a tremendous burden. A single individual may be physically ill but psychologically strong, feel despair about family but contentment about work, and experience great dissatisfaction but a profound sense of meaning in life. Furthermore, what is considered successful according to functional norms might not meet with ideal norms, nor square with statistical norms. Definitions of the meaning of success have changed over historical time and will continue to vary along with changes in societal, cultural, and biological norms. Definition of outcomes, therefore, needs to be multidimensional and multilevel and needs to consider both gains and losses.

Furthermore, the research question needs to be broadened from a primary focus on outcomes; that is, from: 'What is successful ageing?' to include 'How do people age successfully?' or 'What are the processes that allow for mastery of goals in old age?' We suggest that understanding the processes that people use to reach their goals under increasing limitations in resources, be they social, psychological or biological, will lead to additional insights and progress in the field. In this paper we argue that the metamodel of selective optimisation with compensation (Baltes and Baltes 1990) offers a suitable framework within which to pose such questions. The proposed model defines success as the attainment of goals which can differ widely among people and can be measured against diverse standards and norms. The three processes identified in the model - namely, selection, compensation and optimisation - in concert, provide a way to conceptualise the strategies older people use to age well even in the face of loss. We cannot predict what any given individual's successful ageing will look like until we know the domains of functioning and goals that that individual considers important, personally meaningful and in which he or she feels competent.

To provide a context for our argument, we begin by tracing the history of theoretical attempts to define and describe success and successful ageing. Next, we examine empirical findings for the most commonly used criteria of successful ageing. Last, we introduce the process model of selective optimisation with compensation (Baltes 1987; Baltes and Baltes 1990), a metamodel of successful ageing that incorporates a life-span view, builds on empirical evidence about gains and losses in old age, permits specification of any desired goal and/or norm to define success depending on the theoretical perspective embraced, and specifies three processes that facilitate striving toward goals in the face of losses. 


\section{Defining success and successful ageing}

Definitions of success have varied throughout history, implying greater or lesser involvement of luck and/or effort and more or less in the way of evaluative connotations, e.g. a fortunate outcome versus any outcome (Edwards I 967 ; Simpson and Weiner I 989). In modern usage, success typically refers to favourable attainments deriving from one's own behaviour and actions. Very often it is measured by economic accomplishments. Because of such materialistic usages, success is considered by some to be a poor choice for describing positive outcomes in old age. Cole (1984), for example, views the current emphasis on successful ageing as the capitalist takeover of ageing.

Success, however, is not explicitly limited to utilitarian outcomes. Success can refer to the attainment of personal goals of all types, ranging from the maintenance of physical functioning and good health to generativity, ego-integrity, self-actualisation and social connectedness (see Baltes and Silverberg I994; Bellah et al. I 986).

Some critics argue that successful ageing is an oxymoron; successful ageing means not ageing at all. History, as well as our modern youthand-achievement-oriented culture, is replete with tales of the 'Jungbrunnen' or 'fountain of youth' and consumer products that aim to help people maintain a youthful appearance, increase productivity, and optimise physical health. However, a conceptualisation of successful ageing founded on denial is ultimately an untenable position. Looking back and seeking to cultivate the still glorious middle years will inevitably lead to despair and eventual defeat (Erikson 1959; Butler i 974 ).

Unlike earlier developmental stages in which goals and success are defined as the acquisition of survival skills, successful ageing is intricately interwoven with a sense of meaning and purpose in life and thus invokes existential paradigms or ideals (Cole I984; Cole and Gadow I986; Rosenmayr I983a, $b$; 1985). Rentsch (1992) observes that ageing is the radicalisation of the human condition. Ageing is described as a dialectic between self-actualisation and self-alienation.

Although influenced heavily by the cultural context of the historical era, a deep ambivalence about ageing can be traced from ancient to modern times. With the advent of industrial capitalism, human value became equated with productivity and, at the same time, retirement was institutionalised as a symbol of non-productivity. Ironically, this more negative view of old people and ageing was facilitated by scientific attention to ageing. By focusing almost exclusively on problems of elderly people - their isolation, dependence, role-loss and illness, - researchers reinforced a very negative portrayal of ageing. 
The view of ageing as a time of decline was further reinforced by wellintentioned advocates and politicians who, in order to win support for the infirm elderly, portrayed them as sick and needy. The implementation of the Older Americans Act (OAA) and similar policies in the U.S. and other countries functioned as a double-edged sword by providing protection but also endangering individual autonomy and integrity (Estes and Binney r 989; Guillemard 1992).

The last two decades have witnessed several important changes in the views of old age held by the scientific community. Findings in biological, social and psychological spheres have pointed to unused and latent potentials of elderly adults. Examples are found in the domain of cognitive ageing, where it has been shown that elders can improve their cognitive output after improved learning and performance conditions (P. B. Baltes and Lindenberger I988; Schaie 1990); in the domain of social behaviour, where dependent self-care behaviour can be reversed to independent functioning when given prompts, time and rewards (Baltes 1995; for review see Mosher-Ashley 1986/87); and in the domain of physical functioning, where it has been shown that a great number of physical declines can be postponed and temporarily reversed through proper exercise and diet (Baltes and Reichert 1992; Stones and Kozma 1985; Whitbourne 1985). A wealth of empirical findings from both the social and biological sciences have accrued confirming that latent potentials can be activated to compensate for possible losses in old age.

Thus, there appears to be considerable fluidity in old age. Nevertheless, gerontological theories have either focused on decline or growth. None that we know of have considered gains and losses and their potential interactions conjointly. Many early theories of successful ageing posited highly idealised human states as the adaptive outcomes of old age. Jung (193I), for example, postulated expansion beyond gender constraints towards full humanity and wisdom as criteria for successful ageing. Erikson's stage model (1984; Erikson et al. 1986) posited that psychological peace and ego integrity were the criteria for success in old age. Other theorists conceptualised the acceptance of decline as the adaptive task of old age (i.e. Bühler 1933). The now classic disengagement theory (Cumming and Henry $196 \mathrm{I}$ ) characterised success as acceptance of and reconciliation with the loss of power endemic in old age, whereas activity theory (Havighurst and Albrecht 1953; Maddox 1965) posited that the maintenance of activity, replacement of lost roles with new ones and continued psychological involvement in society and interpersonal relationships represented the formula for successful ageing.

More recently, Ryff (1982; 1989a,b) proposed an integrative model 
of successful ageing based on developmental, clinical, and mental health perspectives arguing that multiple aspects of life must be considered when assessing successful ageing. Her model includes six dimensions, all refering to positive functioning: self-acceptance, positive relations with others, autonomy, environmental mastery, purpose in life, and personal growth.

In summary, over the past 50 years, a number of theories have been proposed to describe successful ageing. The centrepiece of most of these conceptualizations has been the elaboration of focal success outcomes, ranging from disengagement to longevity. No one theory, criterion or even pattern of criteria has been widely accepted as a cogent prescription or explanation for success in old age. Part of this might be due to the empirical findings on successful ageing to which we now turn.

\section{Empirical findings for successful ageing criteria}

Physical health, functional autonomy, and longevity have served as indicators of successful ageing to biological scientists. Physical health is unquestionably tied to psychological well-being at any age (Bowling and Brown 1991; Krause 1990; Rodin 1986) and psychological variables, like perceived social support and life style, appear to influence morbidity and mortality (Blazer 1982 ; House et al. I988; Vaillant 1990 ).

However, good physical health cannot be a prerequisite in psychological theories of successful ageing because, as Wong points out, 'even the fittest [eventually] succumb to disabling illness' (1918: $5_{18} 8$ ). In addition, the person who has lived the longest, most likely will also have experienced the most losses, be they loss of friends, loss of own health, etc. The person who strives for autonomy may, at the same time, lose social contacts and experience isolation. Thus, the criteria of functional autonomy and longevity do not necessarily lead to psychological well-being.

Successful ageing, when studied empirically by psychologists, is most commonly operationalised as life satisfaction, high morale or the subjective appraisal of well-being. Researchers have used life satisfaction as an index of success in the retirement transition (Parnes I98 I), recovery after widowhood (Wortman and Silver 1990) and a number of other live events. The voluminous literature about the direct and indirect effects of social structural variables on satisfaction (George 
1990) reveals that statistically significant differences in satisfaction among groups of people do exist. Income, population density, marital status, years of formal education, and other variables do predict life satisfaction but account for very little of the variance in life satisfaction.

Moreover, the vast majority of people report that they are satisfied with their lives regardless of objective indicators (Brim 1988, 1992; Diener I 984; George I98 I; Larson I978; Lawton I983, I984; Schwarz and Strack 1989). One possible explanation is that life satisfaction comprises different dimensions in the old versus the young (Ryff $1989 b)$. Another explanation for preserved life satisfaction in spite of age-related loss is, however, that elderly people adapt to negative changes by using coping strategies such as downward social comparison (Wills 199I).

Relatively recently, a number of researchers from diverse fields, i.e. psychology (Dittmann-Kohli i990; Reker et al. 1987; Wong 1989), literature (Weiland 1989; Woodword and Schwartz 1986) and history (Cole 1984), have shifted their attention to personal meaning in life as an index of successful ageing. Wong ( 1989 ) following Jung (I93I) and Erickson and colleagues ( 1986 ) argue that finding personal meaning in life is the major developmental task of old age. Personal meaning has been conceptualised as the interpretation of life (Antonovsky 1979), the central focus on values (Cole and Gadow I 986), the cognitive construal of consistency between goals and actions (Rosenmayr 1985), the acceptance of immutable circumstances and integrative reminiscence (Wong 1989, I991; Wong and Watt I99I), self-discovery (Tournier 1972), future-orientedness and optimism (Schonfield 1973), and as religiosity and spirituality (Cole I984).

\section{Summary}

We agree with Cole (1984) and Rosenmayr (1985) that a rethinking of successful ageing is necessary in order to avoid a class bias or utopian dream. We disagree, however, that a positive view of the potential of ageing necessarily includes a prescription for the outcome, or places sole responsibility for successful ageing on the individual.

We argue that most gerontological theories do not take into account individual or cultural variation in goals and usually apply ideal and/or statistical norms from within one culture, rarely functional or individual norms. But no one criterion has been found acceptable. Indeed, even ranking the array of success criteria is difficult. Can an old person in excellent physical health but deteriorated mental health be 
TA B LE I. Different norms in different domains with different goals

\begin{tabular}{|c|c|c|c|}
\hline \multirow[b]{2}{*}{ NORM } & \multicolumn{3}{|c|}{ Domains/Goals } \\
\hline & physical health & social integration & $\begin{array}{l}\text { psychological } \\
\text { well-being }\end{array}$ \\
\hline $\begin{array}{l}\text { Statistical } \\
\text { Ideal } \\
\text { Functional }\end{array}$ & $\begin{array}{l}\text { no major disease } \\
\text { complete health } \\
\text { hearing }\end{array}$ & $\begin{array}{l}\text { marriage } \\
\text { intimacy } \\
\text { communication }\end{array}$ & $\begin{array}{l}\text { no pathology } \\
\text { happiness } \\
\text { independence }\end{array}$ \\
\hline
\end{tabular}

considered a successful ager? Should people who live only to 70 , but maintain a highly optimistic view of ageing be considered unsuccessful agers? A multicriteria approach is preferred to a monocriterion approach (Ryff i $989 a ;$ i $99 \mathrm{I}$ ). However, unless we accept all criteria as equally important - which would render the numbers of successful ageing people extremely small-we are left with the problem of ranking the most important criteria.

A solution to this problem seems to be a flexible definition of success outcomes. Success can be defined by different authorities (e.g. individual, peer group, society, scientific theory), by different criteria of assessment (e.g. subjective vs. objective) and by different norms (e.g. functional, statistical, ideal norm). ${ }^{1}$ On the most general level, successful ageing implies that people reach personal goals; these might coincide with ideal or statistical norms but may also concur with idiosyncratic goals. Table I provides an overview and examples of different standards of success.

Allowing variation in goals and norms and identifying the prototypical processes that facilitate successful ageing will potentially lead to increasing precision and strength of our theories of successful ageing and the construction of environmental conditions and life styles conducive to optimal ageing. In short, success needs to be redefined such that it is not just associated with normative and ideal goals or outcomes. Success does not and should not be measured against one standard. Any definition of success based exclusively on theoretically normative outcomes and goals will, by its very nature, lack generalisability and longevity. When the question becomes: How is success achieved?, we may find that the processes people use to cope with life and ageing are more universal and less dependent on cultural vicissitudes. ${ }^{1}$ 


\section{The metamodel of selective optimisation with compensation}

With this said, a useful model of successful ageing must account for the dynamics between gains and losses; that is, on the one hand, for a reduction in reserves and an increasing number of specific losses and challenges in the biological, social, and psychological spheres; and, on the other hand, for potential growth and plasticity in old age. Such a metamodel should be able to harbour a great diversity of outcomes/ goals, accommodate different success criteria, and emphasise how elderly people obtain personal goals - that is, age successfully - in the face of simultaneous losses.

In life-span psychology (P. B. Baltes 1987, 1991; P. B. Baltes et al. I 980 ), the major criterion for successful development is the efficacious functioning of the individual in an identified system (biological, social, psychological), domain (sports, leisure, job, family) or task (selfactualisation, cognitive performance, social integration. To augment and enrich one's own reserve capacities and resources, particularly throughout early and middle life, is of the utmost importance since these will also assist successful mastery of developmental tasks in late life. While adherence to the notion of efficacious functioning does not preclude the prescription of developmental goals or outcomes as ideal in successful ageing, it does not bank on them and above all, it allows the operation of diverse norms to evaluate attainment of individually desired goals. Such a model implicitly and explicitly allows for greater variability in successful ageing, with the base being heterogeneity and plasticity, two major findings known about ageing (Baltes and Baltes I 990).

In this sense, the metamodel of selective optimisation with compensation (SOC) (P. B. Baltes and Baltes 1990; Baltes 1987; Baltes and Reichert 1982 ) defines success as goal attainment and successful ageing as minimisation of losses and maximisation of gains. Using the notion of mastery and adaptation allows diverse specifications of the goals and its evaluation criteria depending on the specific theory tested.

The metamodel specifies three processes: selection, compensation, and optimisation. If implemented together, use of the processes enables people to master their goals despite, or perhaps even because of, losses and increasing vulnerabilities. The three processes embrace a great multitude of psychological mechanisms and strategies. For instance, optimisation of one's health may mean for one person to exercise more frequently, for another to diet, and for a third person to reduce stress. According to the model, the same processes are at work even when goals vary over individuals, time or context. Furthermore, the criteria 
of goal attainment can vary by type of assessment (objective vs. subjective), by the authority (individual, group, family, culture) judging success, and by norms (statistical, ideal, functional).

A real life example might best illustrate the three processes and their interaction. An old marathon runner can maintain the goal of winning by competing within his own age group and running fewer and 'easier' courses (instances of selection); varying footwear and extending warmup periods (compensation) and using a special diet and vitamins to increase fitness (optimisation).

The metamodel, thus, is considered prototypical in its genotype of mastery, but it can accommodate wide interindividual differences in its phenotypic manifestation. What and how many domains people choose and the specific strategies they use in striving towards successful ageing may differ from person to person. The model is a metamodel that attempts to represent scientific knowledge about the nature of development and ageing with the focus on successful adaptation. Although the three processes have theoretical implications for successful development at large (see Marsiske et al. 1995), we will focus here on successful ageing.

\section{Definition of the three component processes and empirical evidence}

\section{Selection}

Selection at all levels of behaviour (input, processing, output) is a core element of any theory of behaviour. Selection can be active or passive, internal or external, intentional or automatic. In development including ageing, selection refers to the increasing restriction of life domains as a consequence or in anticipation of changes in personal and environmental resources. In old age, these changes are often losses. Selection can entail the avoidance of one domain altogether or it can mean a restriction in tasks and goals within one or more domains. An elderly person whose spouse is suffering from a terminal illness, for example, may give up the domain of sexuality altogether, or may restrict some goals and involvements in the social network at large, but increase efforts in the domain of leisure activities and family. The adaptive task of the individual is to select high priority domains, tasks, and goals that involve a convergence between environmental demands, individual motivations, skills and biological capacity.

Although selection connotes a reduction in the number of high- 
efficacy domains, tasks, and goals, it is not necessarily limited to a continuation of previous goals and domains, albeit in smaller numbers. Selection can also involve new or transformed domains and goals. Thus, the person who lost a spouse might continue to invest love and care by carrying on the political activities of the spouse, for instance, and maintaining his or her legacy. Selection always entails the readjustment of individual goals. Selection can be proactive or reactive. It can encompass environmental changes (e.g. relocation), active behaviour changes (e.g. reducing the number of commitments), or passive adjustment (e.g. avoiding climbing stairs or allowing somebody to take responsibility). Proactively, through monitoring current functioning, people predict future changes and losses (e.g. death of the spouse) and make efforts to search for tasks and domains that can remain intact even after losses. Selection is reactive when unpredictable or sudden changes force persons to make a selection. If a stroke suddenly severely impairs a person, a decision to remain at home might not be viable, but the person can engage in selection processes about which institution, how much and what kind of self-care, what type of rehabilitation, what activities to engage in, what television programme to watch, and when to write a letter or make a telephone call.

\section{Empirical evidence for selection processes}

Selection is an integral part of any developmental process. Evidence for selection in the form of channelling or canalisation can be found in sociology, biology, and psychology. In sociology, selection operates via social structures such as social class (Mayer and Carroll 1987), race, gender and ethnicity (Jencks 1992), social mobility (Blau and Duncan I 976) as well as via immutable variables such as sex (Mayer et al. I99 I) and age (Hagestadt I990). Dannefer ( 1987 ) has called this process sociogenic differentiation. The cumulative effect of selection on a structural level has been described by Merton ( 1968 ) as the Matthew effect, referring to the self-maintaining properties of particular social paths.

In biology, selection is the term used to explain canalisation and specialisation during biological development (Waddington 1975). Cotman (1985), for instance, argues that specialisation on the cellular level involves the loss of alternate courses of cell differentiation. Ontogenetic selection based on the potentials of the genome is a well known fact that pressures development in specific directions.

In psychology, there is evidence for selection from multiple sources. For Skinner ( 1966 ), for instance, selection played a prominent role in the 
process of shaping. In human development, maturation involves progressive specialisation, which involves both gains and losses. Language provides a particularly elegant example of selection. The ability to learn language is far easier early in life than later and the difficulty in second language acquisition increases as a function of language development (Kellerman and Smith ig86).

In personality psychology, findings stemming from self-efficacy theory (Bandura 1977, 1982, 1991) suggest that agency beliefs guide the search, creation, and acceptance of goals, expectations, and environments. By monitoring competencies and demands via self-efficacy beliefs, a person selects which goals to set, what demands to cope with, when to expend effort and when to compromise. People with strong self-efficacy beliefs perceive losses as challenge; those with weak ones perceive losses as threats (Bandura and Cervone I986; Bandura and Wood I989). The strength of self-efficacy beliefs determines which and how often anticipatory scenarios are constructed and imagined, which means of control are activated, and how quickly an activity or domain is abandoned or compromised (Bandura and Jourden I99I).

Markus and colleagues (Markus and Nurius ig86; Markus and Wurf 1987) have coined the term 'multiple selves', referring to 'actual', 'feared' and 'hoped for' self-schemata that aid and guide the search for new goals. Similarly, the literature on personal control provides yet another body of evidence for selection. Secondary control (Heckhausen and Schulz 1993, I995; Rothbaum et al. 1982) and accommodative coping (Brandtstädter and Renner r 990) refer essentially to cognitive selection strategies in that they involve the reorganisation of goal structures and goal hierarchies so that a fit between personal competence and environmental demands is achieved.

In social psychology, the social cognitive mechanism of social comparison, which serves to motivate or comfort depending on the reference point, also aids in selection. In the face of difficulties and irreversible losses, downward comparison allows people to adjust and maintain a positive evaluation of the self (Taylor I983; Wood I989).

The theory of socioemotional selectivity (Carstensen I99I; I 993) considers selection adaptive in the social arena and specifies goal change as the precipitant to selection. The theory contends that emotional goals become increasingly salient with age and that people engage in active efforts to restructure their social worlds such that they maximise emotionally meaningful experiences. In contrast to the most popular traditional views of social ageing which suggest that maintaining earlier levels of social activity is necessary for happiness in old age (Osgood 1989), socioemotional selectivity theory proposes that 
the judicious reduction of social contact in adulthood (and especially in old age) fosters enhanced emotional satisfaction and is, thus, adaptive. Analysis of longitudinal data shows that emotional closeness with a select few is maintained or increased from young to middle adulthood even though social contact is reduced during the same time period (Carstensen I 992). Even in very old age, a time when social networks are notably reduced, emotionally close relationships appear to be maintained while more peripheral social relationships are discarded (Lang and Carstensen 1994).

The field of human factors is another research area demonstrating empirical evidence for selection. In studies of driving behaviour, for instance, it is shown that the elderly driver is faced with an array of physical and environmental barriers (for a summary see the Special Report by the Committee for the Study in Improving Mobility and Safety for Older Persons I988; also Warnes et al. I99 I). Conditions perceived as especially problematic were speed, traffic congestion, complex and confusing signs, unfamiliar streets and freeway interchanges. Although almost all studies are about the sensori-motoric and cognitive deficiencies of the elderly aggravating driving behaviour, there are a few examples for coping strategies. Selections made by elderly people accommodate these deficiencies and environmental barriers. They select not to drive at dusk, dawn or at night or make only short trips in familiar territory; they avoid peak-period driving and reduce risk-taking and aggressive behaviour and instead drive more defensively.

\section{Compensation}

Compensation, the second component factor facilitating mastery of loss in reserves in old age, becomes operative when there are person- or environment-associated changes in means-ends resources; i.e. specific behavioural capacities or skills are lost or reduced below the level required for adequate functioning. Compensation can also become necessary as the result of selection. The organism might have to compensate in domains that are not selected for further enhancement and thus are given less attention and energy. An example is the delegation of activities to somebody else.

Compensation, which can be automatic or planned, refers to the use of alternate means to reach the same goal, i.e. accomplish the same outcome in a specific domain; that is, previous means-end strategies are reassessed. If a goal within a domain that includes a large number of activities and means is well elaborated, the person will not experience 
much trouble in counterbalancing or compensating for a specific behavioural deficiency. If the deficiency is large in scope or if the domains and goals are defined by one or very few activities, compensatory efforts will be more difficult. If, for instance, a master musician defines her expertise only as a soloist, it will be difficult for her to compensate for an incurring impairment, such as hearing loss or arthritis that cuts short her career as a soloist. If, however, she defines her domain of expertise by a number of additional activities aside from playing as a soloist, she may compensate for the impairment by becoming a music teacher, a music critic, or a composer.

Compensation can involve existing behaviours or the acquisition of new skills or construction of new means not yet in ones repertoire. Compensation, thus, differs from selection in that the goal is maintained, but new means are enlisted to compensate for a behavioural deficiency in order to maintain or optimise prior functioning. The element of compensation involves aspects of both the mind and technology. Psychological compensatory efforts include, for example, the use of new mnemonic strategies or external memory aids when internal memory mechanics or strategies prove insufficient. The use of a hearing aid is an example of compensation by means of technology. The world of the handicapped is full of technical means that compensate for impairments and make a more or less independent and successful life possible. An avid reader of literature who becomes blind might learn Braille in order to continue reading or might divert to listening to 'books on tape'. Not only technical means, but human means are often needed to compensate. The assistance of a hand or arm when walking, a hired worker who cooks the meals, or a companion who does the writing may provide the compensatory means that enable elderly people to pursue their lives as fully as possible.

\section{Empirical evidence for compensation}

Compensation is a multifaceted term that has found its way into biology as well as psychology (Bäckman and Dixon 1992). In both fields, compensation is possible because of neural or behavioural plasticity, available to the organism when equilibrium is disturbed. In biology, compensatory efforts follow brain injury and sensory handicaps. In the case of neural plasticity, compensatory efforts are seen as the source for recovery (Bach-y-Rita 1990).

In the area of psychopathology, the vulnerability model of schizophrenia argues for self-healing attempts as compensatory efforts on the part of vulnerable persons to stabilise their psychic equilibrium. Böker et al. 
( 1984 ) demonstrated that persons at high risk for schizophrenia show relatively more attempts than people who are at lower risk to compensate due to heightened vulnerability.

In cognitive psychology, the pragmatics of intelligence are considered to have compensatory power to alleviate deficits in the mechanics of intelligence (P. Baltes 1991; Berg and Sternberg 1985; Salthouse ig84).

In personality psychology, findings from self-efficacy theory suggest that by delegating control to others, proxy control serves a compensatory function (Bandura I982). In contrast to selection, proxy control allows the elderly person to maintain earlier goals through the assistance of others. Paradoxically, delegating control to others can be a powerful mechanism for optimising domains that might otherwise decline. Baltes and her colleagues demonstrated, for example, that dependency can secure and optimise social contact (for reviews see Baltes I 995; Baltes and Wahl I99I).

Socioemotional selectivity theory posits that social selection of longterm friends and loved ones (as opposed to acquaintances or hired aids) helps to compensate for losses in areas such as sensory function or memory impairment (Carstensen 1993). In the case of hearing loss, for example, a familiar social partner is more likely to speak clearly or speak into the 'good ear' than someone unfamiliar with special losses. Gould and colleagues (I99I) showed positive effects of social collaboration in an oral recall task, clearly a process that benefits most from exchanges with familiar others.

Human factors research is replete with empirical findings suggesting compensation (for a summary see Committee for the Study in Improving Mobility and Safety for Older Person 1988; also Warnes et al. 1991). Here too, driving behaviour in the elderly may serve as an illustration. Elderly drivers compensate, for instance, decreased reaction time by driving more slowly and by using interchanges with lights instead of stop signs only; they compensate for loss in peripheral vision by turning their head when changing lanes. Driving can be facilitated by improvements in transportation technology that would tailor more to the elderly driver, such as improvement in readibility of signs, changes in traffic distribution, in certain vehicle design features; in short by compensatory means introduced by the environment not by the elderly person.

In sum, whether the losses are sensory, cognitive or interpersonal, compensation occurs when a certain behaviour (or neural process) is evoked which narrows the gap between actual competence level and environmental demands. 


\section{Optimisation}

Optimisation, the third component factor of SOC, refers to the enrichment and augmentation of reserves or resources and, thus, the enhancement of functioning and adaptive fitness in selected life domains. Optimisation may occur in existing domains (e.g. generativity) or involve investment in new domains and goals consonant with developmental tasks of old age, such as acceptance of one's own mortality. How much selection and compensation must be invested in order to secure maintenance and stimulate optimisation is an empirical question. Recent literature in gerontology suggests that many elderly people, in principle, have the necessary resources and reserves to optimise functions but face restrictive or overprotective environments that inhibit optimisation (Baltes and Wahl 1991). There is no doubt that the process of optimisation will be contingent to a large extent on stimulating and enhancing environmental conditions. Thus, society plays a central role in providing environments that facilitate optimisation. In fact, the success of relatively simple interventions (noted below) suggest that elderly adult often live in a world of underdemand rather than overdemand. Optimisation is dependent upon available possibilities and opportunities, unless older people actively and individually forge new terrain and frontiers (Rosenmayr 1983a,b).

\section{Empirical evidence for optimisation}

The psychological literature is replete with evidence for optimisation processes. Improving performance in selected domains is of great interest in education, sport psychology, and cognitive expertise (see Ericsson et al. 1993, for review).

Within gerontology itself, there is ample evidence for optimisation from intervention studies. This literature evinces plasticity and growth possibilities into very old age. When environmental conditions encourage practice, training and exercise and when attention and motivation are stimulated, declines - long considered to be intractable - can be reversed and improved. This has been demonstrated clearly in the domains of cognition, social behaviour and biology.

A diverse array of intervention studies demonstrates that old people can profit from 'optimising' environments. Physical exercise improves biological functioning such as pulmonary and cardiovascular functions (for a review see Bortz I 989; Whitbourne I 985); cognitive intervention can increase memory performance (P. B. Baltes and Lindenberger 
I 988) and can even help to ameliorate the impact of dementia on daily living (Wiedl et al. 1987); behavioural interventions can reverse chronic dependent behaviours and increase autonomy (Baltes 1995).

On a macro-level, studies of control-enhancing interventions (Langer and Rodin 1976; Rodin and Langer 1977) have become classics. Despite criticisms concerning the underlying change agents (Munson I 989 ), these studies have demonstrated substantial improvement in activity level, health, and life satisfaction following relatively minor institutional modifications. Baltes and her colleagues (I 994) demonstrated an increase in independent behaviours (autonomy) of institutionalised elderly people following an intervention aimed at changing the institutional context from one that overprotects to one that enhances autonomy and independence. By implementing a training programme for caregivers directed at creating greater sensitivity concerning the need for balance between dependency and autonomy (see also Parmelee and Lawton 1990), caregivers of elderly adults relinquished their inadvertent tendency to foster dependency and shifted support toward reinforcing independent behaviour. Results confirm the malleability of social environmental conditions responsible for dependency in elderly people.

In addition to micro- and macro-level intervention studies, indirect evidence for optimisation in late life can be found in empirical tests of socioemotional selectivity theory. Not only are older couples happier than younger couples (which could be explained by selective attrition), studies of emotion regulation in intimate relationships in old age suggest that, compared to middle-aged couples, older couples display more efforts to quell emotional conflict, i.e. express more affection to their partner while voicing concerns (Carstensen et al. I 995) and report greater enjoyment from discussions about children, grandchildren, dreams, vacations and doing things together and less conflict surrounding money, religion, recreation and children (Levenson et al. I 993).

\section{Summary and conclusions}

The aim of this paper is to advocate a process-oriented approach to successful ageing. We argue that the search for normative success outcomes in old age, whether longevity, ego-integrity or life satisfaction, will ultimately hold limited benefits due to the vast heterogeneity inherent in human ageing. Theoretically derived ideals of what old age and old people should be like have been debated and challenged over 
the years. Multicriterial approaches have been offered, yet the focal thrust of this work remains on measuring success or the lack thereof according to normative standards.

We feel that a process-oriented approach has three advantages. First, by accepting personal goals as success outcomes, whatever they may be, a process-oriented approach avoids the problem of imposing universal values and standards. It both acknowledges the heterogeneity of ageing people and avoids the inevitable lack of precision inherent in applying global constructs across diverse groups of people.

Second, a process-oriented approach directs attention to the strategies people use to master specific personal goals. This type of approach accentuates the functional properties of behaviours and strategies. Even behaviours that initially may appear maladaptive, such as limiting social contact, are revealed as adaptive once their function is examined. Consider also a request for assistance walking to the music room. When made by an individual whose primary goal is to continue playing the piano, such a request may be considered compensatory and adaptive. Yet if the individual's goal is to maintain muscular strength, the same behavioural profile may be viewed as maladaptive. In short, in a process-oriented approach classification of goals and strategies rather than outcomes alone becomes the focus.

Third, the process-oriented approach we advocate considers the interplay of gains and losses inherent in old age. Rather than deny the inevitable losses that all old people experience in advanced age, the selective optimisation with compensation model implies that old age holds the potential to be a time when the accumulated knowledge and expertise of a life-time is invested in the realisation of a distilled set of highly meaningful domains and goals. In this view, even losses may lead to gains in some highly valued areas of life.

Clearly, more research is needed before the merits of a processoriented approach will be known. Initial findings from the Berlin Aging Study (see Ageing and Society 1993: 13) are highly encouraging. Evidence for the three processes are found, for instance, in the domain of everyday competence (Baltes and Horgas in press; Baltes et al. in press; Marsiske et al. 1994) and in the area of self and personality (Staudinger et al. in press). Although there is ample evidence of each individual component process of the model, there has been virtually no research on the manner in which the components work together. Whether there is a hierarchy among the three component processes remains an empirical question, for example. It may be that compensation is always attempted first, and only when it fails do selections occur. 
We suspect that all three components are activated more easily and readily when there is a rich array of resources available from which to draw. When resources become depleted, an increasingly fine-tuned and subtle interplay among the three components is necessary. We contend, however, that even very frail people can select, compensate and optimise to maximise goal attainment. Given overwhelming evidence that increased loss is associated with ageing, we also suspect that selection and compensation are necessary precursors to optimisation. The time and energy invested in optimising one domain, task or goal will necessarily influence one's involvements in other domains. The longitudinal extension of the Berlin Aging Study promises some answers to these questions.

The model of selective optimisation with compensation also suggests new approaches to research. Experimental manipulation of losses could be simulated to study whether, when, and how selective, compensatory and optimising processes are implemented and to provide precision and strength to predictions about the interplay among processes and goals across people. On a descriptive level, study participants could be selected for similarity in goals in order to analyse the processes used to reach these goals and assess success.

In conclusion, the model proposed in this paper represents a qualitative departure from the traditional social science approach to successful ageing, moving away from a focus on prescribed outcomes and ideal or statistical norms to an analysis in which the primary focus is on the processes people use to obtain desired goals. Skinner ( $198_{3}$ ), in an account of his own ageing, gave eloquent advice on intellectual management to preserve and continue high productivity in light of failing reserves. It was clear from his writings that the intellectual domain was of high priority and that his life was designed around maximising function in this selected domain as opposed to others. We argue that this type of selective optimisation with compensation may be the most important tool for successful ageing.

\section{References}

Antonovsky, A. 1979 Health, Stress, and Coping. Jossey Bass, San Francisco, CA.

Bach-y-Rita, P. I 990 . Brain plasticity as a basis for recovery of function in humans. Neuropsychologia, 28, 547-554.

Bäckman, L. and Dixon, R. A. 1992. Psychological compensation: A theoretical framework. Psychological Bulletin, 112, 259-283.

Baltes, M. M. 1987. Erfolgreiches Altern als Ausdruck von Verhaltenskompetenz und Umweltqualität (Successful Aging as a Product of Behavioral Competence and Environmental Quality). In C. Niemitz (ed) Der Mensch im Zusammenspiel von Anlage 
und Umwelt (Men as product of heredity and environment). Suhrkamp, Frankfurt, $353-37^{6}$.

Baltes, M. M. 1995. Dependency in old age: gains and losses. Current Directions in Psychological Science, 4, 14-1 9.

Baltes, M. M. and Horgas, A. in press. Long-term care institutions and the maintenance of competence. In Schaie, K. W. and Willis, S. L. (eds), Societal mechanisms for maintaining competence in old age. Springer, New York.

Baltes, M. M., Lang, F. and Wilms, H.-U. in press. Kompetenzerhaltung als Ergebnis einer selektiven Optimierung mit Kompensation. In Kruse, A. (ed) Jahrbuch der medizinischen Psychologie: Psychosoziale Gerontologie. Hogrefe, Göttingen.

Baltes, M. M., Neumann, E.-M. and Zank, S. 1994. Maintenance and rehabilitation of independence in old age: an intervention program for staff. Psychology and Aging, 9, I 79-188.

Baltes, M. M. and Reichert, M. 1992. Successful aging: the product of biological factors, environmental quality, and behavioral competence. In Ebrahim, S. (ed) Health Care for Older Women. Oxford University Press, Oxford, 236-256.

Baltes, M. M. and Silverberg, S. B. 1994. The dynamics between dependency and autonomy across the life-span. In Featherman, D., Lerner, R. and Perlmutter, M. (eds) Life-span Development and Behavior. Erlbaum, Hillsdale, NJ, 12, 41-go.

Baltes, M. M. and Wahl, H.-W. I $99 \mathrm{I}$. The behavior system of dependency in the elderly: interaction with the social environment. In Ory, M., Abeles, R. P. and Lipman, P. D. (eds) Aging, Health and Behavior. Sage, Beverly Hills, 83-ı6.

Baltes, P. B. 1987 Theoretical propositions of life-span developmental psychology: on the dynamics between growth and decline. Developmental Psychology, 23, 6 I I $_{1}-626$.

Baltes, P. B. I991. The many faces of human aging: toward a psychological culture of old age. Psychological Medicine, 21, 837-854.

Baltes, P. B. and Baltes, M. M. I 990 . Psychological perspectives on successful aging: The model of selective optimization with compensation. In Baltes, P. B., Baltes, M. M. (eds) Successful Aging: Perspectives from the Behavioral Sciences. Cambridge University Press, New York, I-34.

Baltes, P. B. and Lindenberger, U. 1988 . On the range of cognitive plasticity in old age as a function of experience: I 5 years of intervention research. Behavior Therapy, 19, $283-300$.

Baltes, P. B., Reese, H.W. and Lipsitt, L. P. 1980. Life-span developmental psychology. Annual Review of Psychology, 31, 65-1 10.

Bandura, A. 1977. Self-efficacy: toward a unifying theory of behavioral change. Psychological Review, 84, I91-215.

Bandura, A. 1982. Self-efficacy mechanisms in human agency. American Psychologist, 37, 122-147.

Bandura, A. 1991. Self-regulation of motivation through anticipatory and self-reactive mechanisms. In Dienstbier, R. A. (ed) Nebraska Symposium on Motivation, 1990. University of Nebraska Press, Lincoln, NE, 38, 69-164.

Bandura, A. and Cervone, D. I 986 . Differential engagement of self-reactive influences in cognitive motivation. Organizational Behavior and Human Decision Processes, 38, 92-113.

Bandura, A. and Jourden, F.J. r 991 . Self-regulatory mechanisms governing socialcomparison effects on complex decision making. Journal of Personality and Social Psychology, 6o, 94I-95I.

Bandura, A. and Wood, R. I989. Effect of perceived controllability and performance standards on self-regulation of complex decision making. Journal of Personality and Social Psychology, 56, 805-8I5.

Bellah, R. N., Madison, R., Sullivan, W. K., et al. 1986. (eds) Habits of the Heart. Individualism and commitment in American life? University of California Press, Berkeley. 
Berg, C. A. and Sternberg, R. J. 1985. A triarchic theory of intellectual development during adulthood. Developmental Review, 5, 334-370.

Blau, P. M. and Duncan, O. D. 1976. The American Occupational Structure. Wiley, New York.

Blazer, D. 1982. Social support and mortality in an elderly community population. American Journal of Epidemiology, 115, 684-694.

Böker, W., Brenner, H. D., Gerstner, G., Keller, F., Müller, J. and Spichtig, L. I 984. Self-healing strategies among schizophrenics: attempts at compensation for basic disorders. Acta Psychiatrica Scandinavia, 69, 373-378.

Boesch, E. 1954. Über die klinische Methode in der psychologischen Persönlichkeitsforschung. Zeitschrift für diagnostische Psychologie, 2, 275-292.

Bortz, W. M. 1989. Redefining human aging. Journal of the American Geriatrics Society, 37, 1092-1 096 .

Bowling, A. and Browne, P. D. I991. Social networks, health, and emotional wellbeing among the oldest old in London. Journal of Gerontology, 46, 20-32.

Brandtstädter, J. and Renner, G. 1990. Tenacious goal pursuit and flexible goal adjustment: explication and age-related analysis of assimiliative and accommodative strategies of coping. Psychology and Aging, 5, 58-67.

Brim, O. G. 1988. Losing and winning: the nature of ambition in everyday life. Psychology Today, 9, 48-52.

Brim, O. G. 1992. Ambition. Basic Books, New York.

Brody, J. A., Brock, D. B. and Williams, T. F. 1987. Trends in the health of the elderly population. Annual Review of Public Health, 8, 2 I 1-234.

Bühler, Ch. 1933. Der menschliche Lebenslauf als psychologisches Problem (The Human Life Course as Psychological Problem). Hirzel, Leipzig.

Butler, R. N. (1974). Successful aging and the role of the life review. Journal of the American Geriatrics Society, 22, 529-535.

Carstensen, L. L. I991. Socioemotional selectivity theory: social activity in life-span context. Annual Review of Gerontology and Geriatrics, I I, 195-2 I 7.

Carstensen, L. L. 1992. Social and emotional patterns in adulthood: support for socioemotional selectivity theory. Psychology and Aging, 7, 331-338.

Carstensen, L. L. I993. Motivation for social contact across the life span. A theory of socioemotional selectivity. In Jacobs, J. (ed) Nebraska Symposium on Motivation: Developmental Perspectives on Motivation. University of Nebraska Press, Lincoln, 4o, 209-254.

Carstensen, L. L., Gottman, J. M. and Levenson, R. W. 1995. Emotional behavior in long-term marriage. Psychology and Aging, 10, 140-149.

Cole, T. R. 1983. The 'enlightened' view of aging: Victorian morality in a new key. Hastings Center Report, 13, 34-40.

Cole, T. R. 1984. Aging, meaning, and well-being: musings of a cultural historian. International Journal of Aging and Human Development, 19, 329-336.

Cole, T. R. and Gadow, S. D. (eds) 1986. What Does It Mean to Grow Old? Duke University Press, Durham.

Committee for the Study on Improving Mobility and Safety for Older Persons 1988. (eds) Transportation in an aging society: Improving mobility and safety for older persons, Special Report 218, I and 2. National Research Council, Washington, D.C.

Cotman, C. W. (ed) r 985 . Synaptic Plasticity. Guilford Press, New York.

Cumming, E. and Henry, W. E. 196 r. Growing Old: The Process of Disengagement. Basic Books, New York.

Dannefer, D. 1987 . Aging as intracohort differentiation: accentuation, the Matthew effect, and the life course. Sociological Forum, 2, $211-236$.

Diener, E. ${ }_{1984}$. Subjective well-being. Psychological Bulletin, 95, 542-575. 
Dittmann-Kohli, F. 1990. The construction of meaning in old age: possibilities and constraints. Aging and Society, ro, 279-294.

Edwards, P. 1967. Life, meaning and value of. In Edwards, P. (ed) The Encyclopedia of Philosophy. MacMillan, New York, 4, 467-476.

Erikson, E. H. 1959. The problem of ego identity. Psychological Issues, I, 101-164.

Erikson, E. H. 1984. Reflection on the last stage - and the first. Psychoanalytic Study of the Child, 39, I55-165.

Erikson, E. H., Erikson, J. and Kivnick, H. I 986 . Vital Involvement in Old Age. Norton, New York.

Ericsson, K. A., Krampe, R. Th. and Tesch-Römer, C. 1993. The role of deliberate practice in the acquisition of expert performance. Psychological Review, 100, 363-406.

Estes, C. L. and Binney, E. A. I989. The biomedicalization of aging. The Gerontologist, 29, 587-596.

Fries, J. F. 199o. Medical perspectives upon successful aging. In Baltes, P. B. and Baltes, M. M. (eds) Successful Aging. Perspectives from the Behavioral Sciences. Cambridge University Press, New York, 35-49.

George, L. K. I98ז. Subjective well-being: conceptual and methodological issues. Annual Review of Gerontology and Geriatrics, 2,345-382.

George, L. K. 1990. Social structure, social processes, and social-psychological states. In Binstock, R. H. and George, L. K. (eds) Handbook of Aging and the Social Sciences. Academic Press, New York, I 86-204.

Gould, O. N., Trevithick, L. and Dixon, R. A. I99I. Adult age differences in elaborations produced during prose recall. Psychology and Aging, 6, 93-99.

Guillemard, A.-M. 1992. Europäische Perspektiven der Alternspolitik (European perspectives of politics in aging). In Baltes, P. B. and Mittelstraß, J. (eds) Zukunft des Alterns und gesellschaftliche Entwicklung (Future of Aging and Societal Development). De Gruyter, Berlin, 6r 4-639.

Hagestad, G. O. 1990. Social perspectives on the life course. In Binstock, R. and George, L. (eds) Handbook of Aging and the Social Sciences. Academic Press, New York, 3rd ed., $15^{1-168 .}$

Havighurst, R. J. and Albrecht, R. 1953. Older People. Longmans, New York.

Heckhausen, J. and Schulz, R. 1993. Optimization by selection and compensation: balancing primary and secondary control in life span development. International Joumal of Behavioral Development, 16, 287-303.

Heckhausen, J. and Schulz, R. 1995. A life-span theory of control. Psychological Review, ro2, 284-304.

Herzog, A. R. and Rodgers, W. L. I98I. Age and satisfaction. Data from several large surveys. Research on Aging, 3, 142-165.

House, J. S., Landis, K. R. and Umberson, D. 1988 . Social relationships and health. Science, 24I, 540-545.

Jencks, C. 1992. Rethinking Social Policy: Race, Poverty and the Underclass. Harvard University Press, Cambridge, MA.

Jung, C. G. I93 I. Die Lebenswende (Life's turning point). In Jung, C. G. Seelenprobleme der Gegenwart (Psychological Problems of Today). Rascher, Zürich, 248-274.

Kellerman, E. and Smith, M. S. 1986. Crosslinguistic Influence in Second Language Acquisition. Pergamon Press, Oxford, England.

Krause, N. F. I 990 . Perceived health problems, formal/informal support, and life satisfaction among older adults. Journal of Gerontology: Social Sciences, 45, I93-205.

Lang, F. R. and Carstensen, L. L. 1994. Close emotional relationships in late life: Further support for proactive aging in the social domain. Psychology and Aging, 9, $3^{1} 5^{-324}$.

Langer, E. J. and Rodin, J. 1976. The effects of choice and enhanced personal 
responsibility for the aged: a field experiment in an institutional setting. Journal of Personality and Social Psychology, 34, 191-198.

Larson, R. 1978. Thirty years of research on the subjective well-being of older Americans. Journal of Geronlology, 33, 109-125.

Lawton, M. P. 1983 . The varieties of well-being. Experimental Aging Research, 9, 65-72.

Lawton, M. P. I 984 . The variables of well-being. In Malatesta, C. Z. and Izard, C. E. (eds) Emotion in Adult Development. Sage, Beverly Hills, CA, 67-84.

Levenson, R. W., Carstensen, L. L. and Gottman, J. M. 1993. Long-term marriage: age, gender and satisfaction. Psychology and Aging, 8, $301-313$.

Maddox, G. L. 1965. Fact and artifact: evidence bearing on disengagement theory from the Duke Geriatrics Project. Human Development, 8, I $17^{-1} 30$.

Maddox, G. L. 1987 . Aging differently. The Gerontologist, 27, 557-564.

Manton, K. G., Corder, L. S. and Stallard, E. 1993. Estimates of change in chronic disability and institutional incidence and prevalence rates in the U.S. elderly population from the 1982,1984 , and 1989 National Long Term Care Survey. Journal of Gerontology: Social Sciences, 48, 153-166.

Manton, K. G. and Soldo, B. J. I 985 . Dynamics of health changes in the oldest-old: new perspectives and evidence. Milbank Memorial Fund Quarterly, 63, 206-285.

Markus, H. and Nurius, P. 1986. Possible selves. American Psychologist, 4r, 954-969.

Markus, H. and Wurf, E. 1987 . The dynamic of self concept. A social psychological perspective. Annual Review of Psychology, 38, 299-337.

Marsiske, M. M., Lang, F. R. and Baltes, M. M. 1994. Beyond routine: competence and social support in the daily lives of older adults. Paper presented at the 13 th Biennial Meeting of the International Society for the Study of Behavioral Development, Amsterdam, Netherlands, June/July 1994.

Marsiske, M. M., Lang, F. R., Baltes, P. B. and Baltes, M. M. 1995. Selective optimization with compensation: life-span perspectives on successful development. In Dixon, R. A. and Bäckman, L. (eds) Compensation for Psychological Defects and Declines: Managing Losses and Promoting Gains. Erlbaum, Hillsdale, NJ, 35-79.

Mayer, K.-U., Allmendinger, J. and Huinink, J. I991. Vom Regen in die Traufe: Frauen zwischen Beruf und Familie (Out of the Frying-pan into the Fire: Women between Job and Family). Campus, Frankfurt.

Mayer, K.-U. and Carroll, G. R. 1987. Jobs and classes: structural constraints on career mobility. European Sociological Review, 3, $14-38$.

Merton, R. K. 1968. The Matthew effect in science: the reward and communication system of science. Science, 199, 55-63.

Mosher-Ashley, P. M. 1986-1987. Procedural and methodological parameters in behavioral-gerontological research: a review. International Journal of Aging and Human Development, 24, $189-229$.

Munson, P. A. 1989. Control and dependency in residential care settings for the elderly: perspectives on intervention. In Fry, P. S. (ed) Psychological Perspectives of Helplessness and Control in the Elderly. Elsevier, Amsterdam, 187-215.

Osgood, N. J. 1989. Theory and research in social gerontology. In Osgood, N. J. and Sontz, H. A. (eds) The Science and Practice of Gerontology. Greenwood Press, New York, 55-87.

Parmelee, P. A. and Lawton, M. P. 1990. The design of special environments for the aged. In Birren, J. E. and Schaie, K. W. (eds) Handbook of the Psychology of Aging. Academic Press, New York, 464-488.

Parnes, H. (ed) $198 \mathrm{I}$. Work and Retirement: A Longitudinal Study of Men. MIT Press, Cambridge, MA.

Reker, G. T., Peacock, E. J. and Wong, P. T. P. $19^{87}$. Meaning and purpose in life and well-being: a life-span perspective. Joumal of Geronlology, 42, 44-49.

Rentsch, Th. 1992. Philosophische Anthropologie und Ethik der späten Lebenszeit 
(Philosophical anthropology and ethics of late life). In Baltes, P. B. and Mittelstraß, J. (eds) Zukunft des Alterns und gesellschaftliche Entwicklung (Future of Aging and the Development of Society). de Gruyter, Berlin, 283-304.

Riley, M. W., Kahn, R. L. and Foner, A. (eds). I 994 . Age and Structural Lag. Wiley, New York.

Rodin, J. I 986 . Health, control, and aging. In Baltes, M. M. and Baltes, P. B. (eds) The Psychology of Control and Aging. Lawrence Erlbaum Associates, Hillsdale, NJ, $139-165$.

Rodin, J. and Langer, E. 1977. Long-term effects of a control-relevant intervention with the institutionalized aged. Journal of Personality and Social Psychology, 35, 897-902.

Rosenmayr, L. $19^{83}$ a. Das Alter - ein Stück bewußt gelebten Lebens (Old age - A Time of Conscious Living). Severin \& Siedler, Berlin.

Rosenmayr, L. $1983 b$. Die späte Freiheit (The Late Freedom). Severin \& Siedler, Berlin.

Rosenmayr, L. 1985. Changing values and positions of aging in Western culture. In Birren, J. E. and Schaie, K. W. (eds) Handbook of the Psychology of Aging. Van Nostrand Reinhold, New York, igo-215.

Rosenmayr, L. $19^{89}$. Wandlungen der gesellschaftlichen Sicht und Bewertung des Alters (Changes in society's perspective toward and evaluation of aging). In Baltes, M. M., Kohli, M. and Sames, K. (eds) Erfolgreiches Altern: Bedingungen und Variationen (Successful aging: Conditions and variations). Huber, Bern, 96-101.

Rothbaum, F., Weisz, J. R. and Snyder, S. S. I 982. Changing the world and changing the self: a two-process model of perceived control. Journal of Personality and Social Psychology, 42, 5-37.

Rowe, J. W. and Kahn, R. L. 1987. Human aging: usual and successful. Science, 237, $143^{-1} 49$.

Ryff, C. D. I $9^{82}$. Successful aging: a developmental approach. The Gerontologist, 22, 209-2 I 4 .

Ryff, C. D. 1989a. Beyond Ponce de Leon and life satisfaction: new directions in quest of successful aging. International Journal of Behavioural Development, 12, 35-55.

Ryff, C. D. $1989 b$. In the eye of the beholder: views of psychological well-being among middle-aged and older adults. Psychology and Aging, 4, 195-2 Io.

Ryff, C. D. I991. Possible selves in adulthood and old age: a tale of shifting horizons. Psychology and Aging, 6, 286-295.

Salthouse, T. A. I984. Effects of age and skill in typing. Journal of Experimental Psychology: General, I 13, 345-371.

Schaie, K. W. (ed) 1983. Longitudinal Studies of Adult Psychological Development. The Guilford Press, New York.

Schaie, K. W. 1990. The optimization of cognitive functioning in old age: predictions based on cohort-sequential and longitudinal data. In Baltes, P. B. and Baltes, M. M. (eds) Successful Aging. Perspectives from the Behavioral Sciences. Cambridge University Press, New York, 94-117.

Schonfield, D. 1973. Future commitments and successful aging. I : the random sample. Journal of Gerontology, 28, 189- 196.

Schwarz, N. and Strack, F. 1989 . Evaluating one's life: a judgment model of subjective well-being. In Strack, F., Argyle, M. and Schwarz, N. (eds) The Social Psychology of Well-being. Pergamon, London.

Simpson, J. and Weiner, E. (eds) ig89. The Oxford English Dictionary (2nd ed, XVII). Clarendon, Oxford, 92-93.

Skinner, B. F. 1983. Intellectual self-management in old age. American Psychologist, 38, 239-244.

Skinner, B. F. 1966. The phylogeny and ontogeny of behavior. Science, 153, $1205-1213$.

Staudinger, U., Freund, A., Linden, A. and Maas, I. in press. Selbst, Persönlichkeit und Lebensgestaltung: Psychologische Widerstandsfähigkeit und Vulnerabilität. In 
Mayer, K. U. and Baltes, P. B. (eds) Die Berliner Altersstudie. Akademie Verlag, Berlin.

Stones, M. J. and Kozma, A. 1985. Physical performance. In Charness, N. (ed) Aging and Human Performance. John Wiley and Sons, New York, 26I-29I.

Taylor, S. E. 1983 . Adjustment to threatening events : a theory of cognitive adaptation. American Psychologist, 38, I I6I-I I 73.

Thomae, H. 1981. The Bonn Longitudinal Study of Aging (BOLSA): an approach to differential gerontology. In Baert, A. E. (eds) Prospective Longitudinal Research. Oxford University Press, Oxford, 165-197.

Tournier, P. 1972. Learning to Grow Old. SCM Press, London.

Vaillant, G. E. 1990. Avoiding negative life outcomes: evidence from a forty-five year study. In Baltes, P. B. and Baltes, M. M. (eds) Successful aging. Perspectives from the behavioral sciences. Cambridge University Press, New York, 332-358.

Waddington, C. H. 1975. The Evolution of an Evolutionist. Edinburgh, Edinburgh University Press, Scotland.

Warnes, A., Rough, B. and Sixsmith, J. 1991. Elderly Drivers and New Technology. Project Report 6, Commission of the European Communities.

Weiland, S. 1989. Aging according to biography. The Gerontologist, 29, 191-194.

Whitbourne, S. K. 1985. The Aging Body. Springer, New York.

Wiedl, K., Schöttke, H. and Gediga, G. 1987 . Reserven geistiger Leistungsfähigkeit bei geriatrischen Psychiatriepatienten und Altenheimbewohnern (Reserves of mental functioning in old psychiatric patients and nursing home residents). Zeitschrift für klinische Psychologie, 16, 29-42.

Wills, T. A. 1991. Similarity and self-esteem in downward comparison. In Suls, J. and Wills, T. A. (eds) Social Comparison. Contemporary Theory and Research. Lawrence Erlbaum, Hillsdale, NJ.

Wong, P. T. P. 1989. Personal meaning and successful aging. Canadian Psychology, 30, 516-525.

Wong, P. T. P. 1991. Existential versus causal attributions: the social perceiver as philosopher. In Zelen, S. (ed) Extensions of Attribution Theory. Springer, New York.

Wong, T. P. and Watt, L. M. 1991. What types of reminiscence are associated with successful aging? Psychology and Aging, 6, 272-279.

Wood, J. V. 1989. Theory and research concerning social comparisons of personal attributes. Psychological Bulletin, 106, 231-248.

Woodward, K. and Schwartz, M. M. (eds) 1986. Memory and Desire: Aging - Literature - Psychoanalysis. Indiana University Press, Bloomington.

Wortman, C. and Silver, C. R. I990. Successful mastery of bereavement and widowhood: a life-course perspective. In Baltes, P. B. and Baltes, M. M. (eds) Successful aging. Perspectives from the Behavioral Sciences. Cambridge University Press, New York, 225-264.

\section{NOTE}

1 Statistical norm means the level of performance, the level of goal attainment that is reached, on average, by a group of people. Ideal norm means the highest goal or possible level of achievement towards that goal, as defined by scientific theory, ideology or social values. Functional norm means the level of achievement necessary for effective functioning in whatever domain. 


\section{Acknowledgements}

The writing of this paper was supported by a research fellowship from the Volkswagen Foundation which allowed the first author a year's stay at Stanford University and NIA grant ROI-AGO88I 6 to the second author. Work on this manuscript was completed in part, while the second author was a Visiting Fellow at the Max Planck Institute for Human Development and Education, Berlin, Germany. We are very grateful to Paul Baltes, Barbara Fredrickson, Frieder Lang, Richard Schulz, and Clemens Tesch-Römer for critical comments on earlier drafts of the paper and to Susan Turk for her patient and careful assistance in researching the literature. Address requests for reprints to: Margret M. Baltes, Department of Gerontopsychiatry, Free University, Ulmenallee 32, $1405^{\circ}$ Berlin I9, Germany, or to Laura L. Carstensen, Department of Psychology, Stanford University, Stanford, CA 94305, USA.

Article accepted 4 October 1995 